\title{
Testing of Locally Available Jordanian Materials for Hydrogen Storage
}

\author{
Yousef A Abdallat ${ }^{1} \&$ Jehad Yamin ${ }^{2}$ \\ ${ }^{1}$ Industrial Engineering Department, School of Engineering, The University of Jordan, Amman 11942, Jordan \\ ${ }^{2}$ Mechanical Engineering Department, School of Engineering, The University of Jordan, Amman 11942, Jordan \\ Correspondence: Yousef A. Abdallat, Industrial Engineering Department, School of Engineering, The University \\ of Jordan, Amman 11942, Jordan. Tel: 962-79502-2007, 962-79960-9750, Fax: 96265300813. E-mail: \\ abdallat@ju.edu.jo,yamin@ju.edu.jo
}

Received: August 24, 2017

Accepted: September 1, 2017

Online Published: October 13, 2017

doi:10.5539/mas.v11n11p9

URL: https://doi.org/10.5539/mas.v11n11p9

\begin{abstract}
Several locally available materials were tested for hydrogen storage. This study was conducted theoretically using suitable software. The materials tested were Sweileh |San, Zeolite, Nickel, Magnesium and Lanthanium. It was found that using the locally available Sweileh sand alone did not give promising results. Pure Magnesium showed the best results followed with Nickle then lanthanium. On mixture basis, adding Magnesium to local Sweileh sand improved its storage ability more than adding other materials like Ni or La.
\end{abstract}

Keywords: metal hydride, hydrogen storage, fuel cell, solid hydrogen storage

\section{Introduction}

The increase in energy consumption particularly in the past several decades has raised fears of exhausting the globe's reserves of natural resources in the future. Due to industrialization and population growth as well as influx of refugees from neighboring conflict areas, today, Jordan largely depend upon natural resources, which are not replaceable. Approximately $90 \%$ of Jordan's energy consumption comes from fossil fuels.

The primary energy consumption consists of Natural gas, crude oil and oil products, imported electricity and renewable energy. The bulk of the consumption in 2011 being Crude oil and related products (Khammash, 2012).

Natural gas is utilized by the Kingdom to generate electricity, with some $80 \%$ of the electricity produced in Jordan depending on the imported gas from Egypt. This is shown below in Figure (1 and 2).

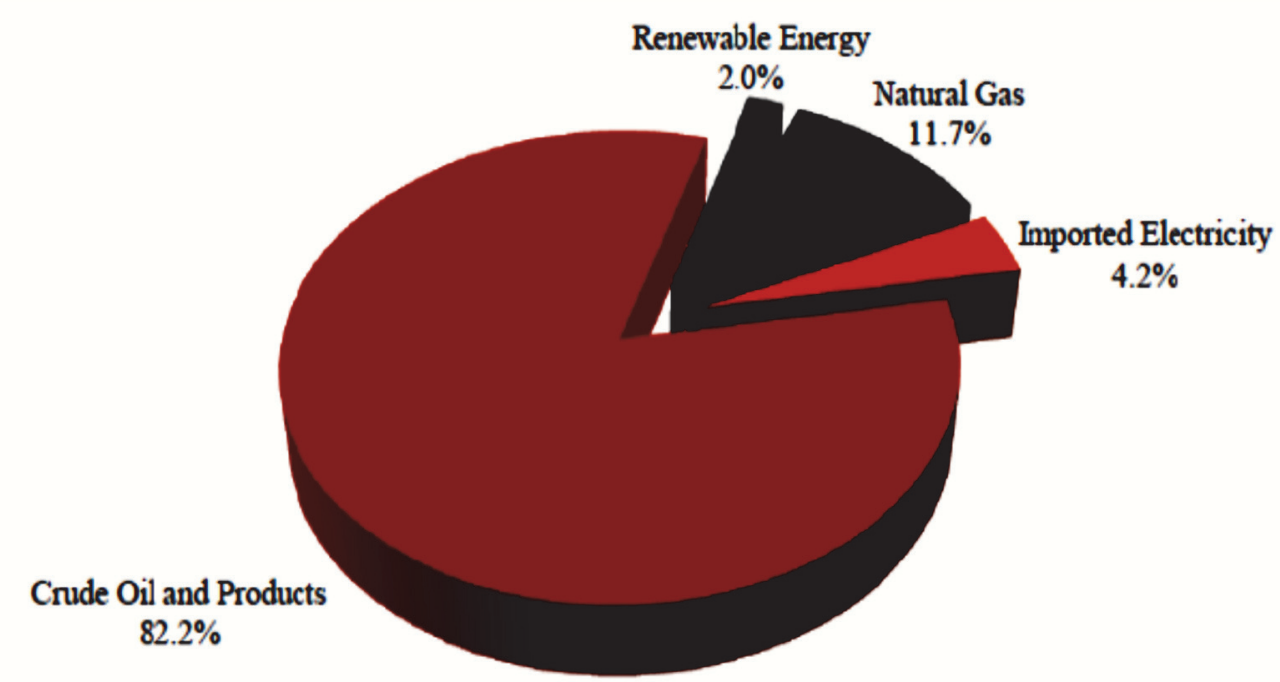

Figure 1. Composition of Primary Consumption in 2011 


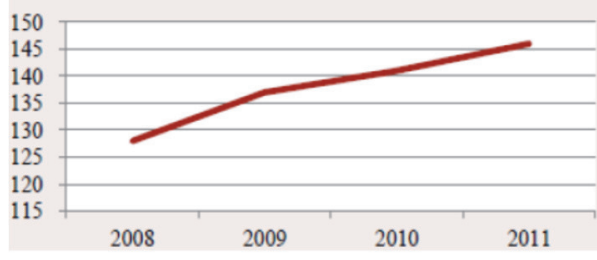

a) Renewable Energy

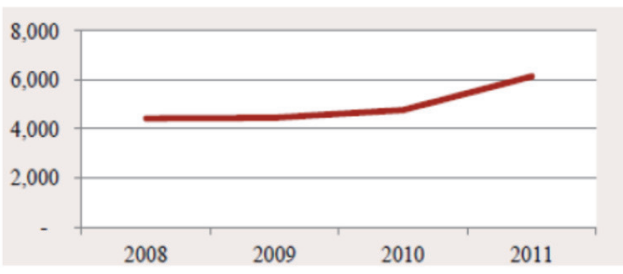

b) Crude Oil \& Products

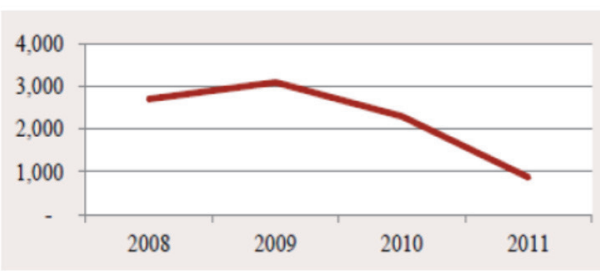

c) Natural Gas

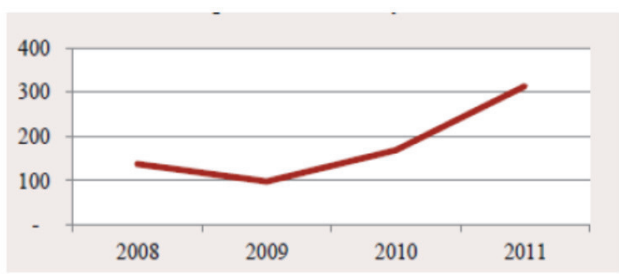

d) Imported Electricity

Figure 2. Primary Energy Consumption in Jordan

The disruption in the supply of natural gas to the Kingdom, which led to a decline in the amounts imported of around $65 \%$ in 2011 compared to 2010, coupled with the increasing burden of the high oil prices, have highlighted the urgency of persevering with the energy master plan to diversify the sources of energy going forward. In 2011, the total cost of imported crude oil, oil products and natural gas reached a whopping JOD3.84 billion, up by $51 \%$ compared to 2010 .

The main objective of this paper is to investigate a potential improvement to hydrogen storage materials for fuel cells using locally available sources in Jordan. It also aims to improve the mathematical model used worldwide with the aim of adding to its accuracy. There are many available materials in Jordan that we can use in Hydrogen storage such as:

\subsection{Silica Sand}

Silica sand is defined as a high purity industrial mineral in which the sand grains are made entirely of quartz. Impurities are very minor. The term silica sand is applied to quartz sand that conforms to the specifications of which the main composition is $\mathrm{SiO}_{2}>99 \%$, with very little contaminant oxide contents (i.e., $\mathrm{Al}_{2} \mathrm{O}_{3}, \mathrm{TiO}_{2}, \mathrm{CaO}_{\text {, }}$ and $\mathrm{Fe}_{2} \mathrm{O}_{3}$ ) and heavy minerals of $<0.1 \%$.

The granules of silica absorbed hydrogen readily and withstood many hydrogen absorption cycles without producing fines. The porosity of the silica matrices was optimized so that the pores were large enough to allow hydrogen to easily move within the matrix and react with the metal hydride particles, but small enough to act as a filter to prevent passage of larger molecule including harmful impurities.

Silica sand are located at Ras En Naqb Area, Petra / Ein El BiadaArea, Al Jayoshia Area and Qa'a Ed Disi Area which have the highest reserve (Madanat, Kailani \& Mehyar, 1998).

\subsection{Zeolite}

Zeolites from a large group of hydrous silicates that show close similarities in composition, association, and mode of occurrence. They are framework aluminasilicates with $\mathrm{Na}$ and $\mathrm{Ca}$, and highly variable amounts of $\mathrm{H}_{2} \mathrm{O}$ in the voids of the framework.

Porous materials have shown that their high surface areas are useful in the desorption of hydrogen. Zeolite absorbs a small amount at room temperature and ambient pressures, meaning it would be an incurred energy cost from maintaining low temperatures and elevated pressures in use. It could be used to enhance pressurized storage systems, and clearly low weight frameworks. The chemical tuning available in zeolites could allow for improved binding of hydrogen.

Zeolitic tuffs are located at Jabal Aritayn (30km NE of Azraq), Tlul Al-shahba (20km E of Al safawi), Tell-Rimah (35km NE of Al Mafraq) and many other small deposits in south and Central of Jordan (Jemni, Nasrallah \& Lamloumi, 1999). 


\section{Mathematical Model}

Before describing the mathematical model and its modifications, the following assumptions are used :

1. Storage is symmetric along the vertical $(Z)$ axis.

2. Thermal equilibrium between solid and gas volumes,

3. Pressure variation in the tank is small, hence, neglected.

4. The effect of the hydrogen concentration on the equilibrium pressure variation is negligible (flat desorption and absorption plateaus on the P-C diagram).

6. The advection terms in the energy equation can be neglected.

7. Hydrogen behaves as an ideal gas.

The first assumption adequately approximates the physical scenario being modeled here since there is likely to be little variation in the convection coefficient or temperature values along the perimeter of the exterior tank walls.

The second through fifth assumptions were validated by two through five are validated by Jemni and Ben Nasrallah (Kikkinides, Georgiadis \& Stubos, 2006). The sixth assumption is a consequence of the third assumption.

As can be concluded from the literature review, 2D models have been found to adequately represent hydrogen adsorption/desorption processes without extra computational complexity. Therefore, present work considers two-dimensional axisymmetric cylindrical geometry. A metal hydride reactor comprises both an expansion volume of length $\mathrm{Lg}$ and abed filled with a LaNi5 metal hydride alloy of length $\mathrm{L}$.

The bed and expansion parts are surrounded by a jacket with the cooling fluid flowing in it. The hydrogen gas enters the storage tank from the cylindrical inlet of the specified radius Rf. In the study of Kikkinides et al. (2006) the heat exchange configuration consisting of additional concentric annular ring and tube demonstrated significant improvement for the hydrogen storage time optimization. Thus, for the current research the same heat exchange system within the bed has been used as shown in Fig. (3):

HE1- inner tube heat exchanger filled with cooling fluid and placed in the center of the reactor from $\mathrm{r}=0$ to $\mathrm{r}=\mathrm{r} 0$;

HE2- inner annular ring heat exchanger for which thickness is specified as $\delta \mathrm{r}=\mathrm{r}_{2}-\mathrm{r}_{1}$ (filled with cooling medium);

HE3- outer surface heat exchanger of radius $r 3$ that surrounds both the expansion volume and porous media.

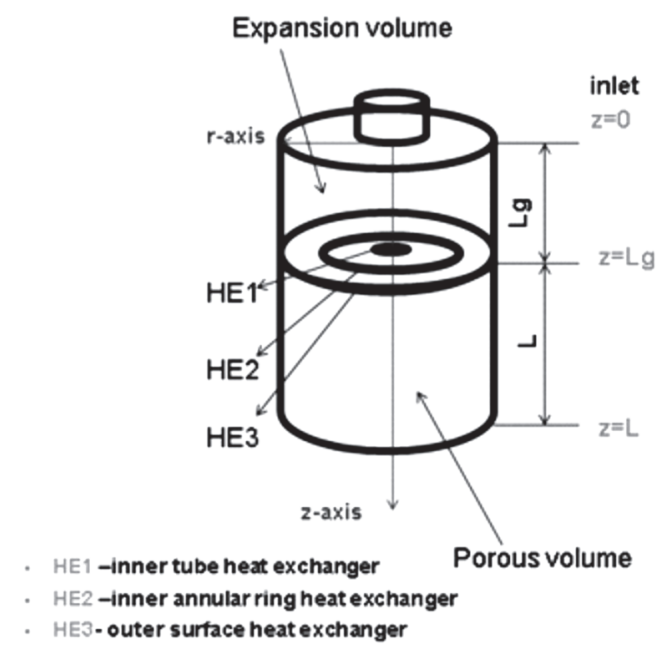

Figure 3. Metal hydride reactor with heat exchangers (in black) inside and outside of the bed

\section{Basic Modeling Equations}

There are many mathematical models in the literature on metal hydrides. All these models describe the same processes that take place during adsorption and desorption in a metal hydrogen reactor. However, significant differences occur in the models presented by different authors due to the scope of model consideration, the presence of additional assumptions, model dimensions, etc. Since 2D models are of particular interest for this research project, some basic modeling equations are discussed below. 


\subsection{Porous Volume}

Mass balance

General mass balances for hydrogen (Eq. 1) and solid (Eq. 2) depending on the rand z axes

$$
\begin{gathered}
\varepsilon \frac{\partial \rho_{\mathrm{g}}}{\partial \mathrm{t}}+\frac{1}{\mathrm{r}} \cdot \frac{\partial}{\partial \mathrm{r}}\left(\mathrm{r} \cdot \rho_{\mathrm{g}} \cdot \mathrm{u}_{\mathrm{r}}\right)+\frac{\partial}{\partial \mathrm{z}} \cdot\left(\rho_{\mathrm{g}} \mathrm{u}_{\mathrm{z}}\right)=-\mathrm{m} \\
(1-\varepsilon) \frac{\partial \rho_{\mathrm{s}}}{\partial \mathrm{t}}=\mathrm{m}
\end{gathered}
$$

Energy balance

Energy balances for metal hydride beds (Eq. 3) can be expressed as a single equation if the assumption of local thermal equilibrium is valid and used for model development.

$$
\left(\rho_{\mathrm{g}} \cdot \mathrm{C}_{\mathrm{p}}\right)_{\mathrm{e}} \cdot \frac{\partial \mathrm{T}}{\partial \mathrm{t}}+\rho_{\mathrm{g}} \cdot \mathrm{C}_{\mathrm{pg}} \cdot \mathrm{u}_{\mathrm{r}} \frac{\partial \mathrm{T}}{\partial \mathrm{r}} \rho_{\mathrm{g}} \cdot \mathrm{C}_{\mathrm{pg}} \cdot \mathrm{u}_{\mathrm{z}} \cdot \frac{\partial \mathrm{T}}{\partial \mathrm{r}}=\frac{1}{\mathrm{r}} \cdot \frac{\partial}{\partial \mathrm{r}}\left(\mathrm{r} \cdot \lambda_{\mathrm{e}} \cdot \frac{\partial \mathrm{T}}{\partial \mathrm{r}}\right)+\frac{\partial}{\partial \mathrm{z}} \cdot\left(\lambda_{\mathrm{e}} \cdot \frac{\partial \mathrm{T}}{\partial \mathrm{z}}\right)-\mathrm{m} \cdot\left(\Delta \mathrm{H}^{\circ}-\mathrm{T}\left(\mathrm{C}_{\mathrm{pg}}-\mathrm{C}_{\mathrm{ps}}\right)\right)
$$

Where;

$$
\begin{gathered}
\left(\rho_{\mathrm{g}} \cdot c_{\mathrm{p}}\right)_{\mathrm{e}}=\left(\mathcal{E} \cdot \rho_{\mathrm{g}} \cdot \mathrm{c}_{\mathrm{pg}}+(1-\varepsilon) \cdot \rho_{\mathrm{s}} \cdot \mathrm{c}_{\mathrm{ps}}\right) \\
\lambda \mathrm{e}=\varepsilon \lambda \mathrm{g}+(1-\varepsilon) \lambda \mathrm{s}
\end{gathered}
$$

In case if the temperatures of solid and gas phases are not equal, a single energy equation is not sufficient to determine the temperature field in the reactor so that energy balances are derived separately.

\section{Momentum balance}

The gas velocity is calculated using either Darcy's law (Eq. 4), i.e. the axial and radial pressure drops depend linearly on the superficial velocity, or more detailed z- and momentum balances. In most of studies reviewed, the Blake-Cozeny equation is used for the model development:

$$
\mathrm{u}=-\frac{\mathrm{k}}{\mu} \operatorname{grad}(\mathrm{P})
$$

\subsection{Expansion Volume}

\section{Mass balance}

The differences between expansion and porous volume mass balances can be easily determined. In case of expansion compartment of the metal hydride reactor, there is no hydrogen adsorbed or desorbed, thus $m$ is equal to 0 , and there is no need to account for the volume porosity since it comprises the gas phase only. This is shown in (Eq.5)

$$
\frac{\partial \rho_{\mathrm{g}}}{\partial \mathrm{t}}+\frac{1}{\mathrm{r}} \cdot \frac{\partial}{\partial \mathrm{r}}\left(\mathrm{r} \cdot \rho_{\mathrm{g}} \cdot \mathrm{u}_{\mathrm{r}}\right)+\frac{\partial}{\partial_{\mathrm{z}}} \cdot\left(\rho_{\mathrm{g}} \cdot \mathrm{u}_{\mathrm{z}}\right)=0
$$

Energy Balance:

Energy balance can also be written as follows :

$$
\rho_{\mathrm{g}} \cdot \mathrm{c}_{\mathrm{pg}} \cdot \frac{\partial \mathrm{T}}{\partial \mathrm{t}}+\frac{1}{\mathrm{r}} \cdot \rho_{\mathrm{g}} \cdot \mathrm{c}_{\mathrm{pg}} \cdot \mathrm{u}_{\mathrm{r}} \cdot \frac{\partial}{\partial \mathrm{r}}(\mathrm{r} \cdot \mathrm{T})+\rho_{\mathrm{g}} \cdot \mathrm{C}_{\mathrm{pg}} \cdot \mathrm{u}_{\mathrm{z}} \cdot \frac{\partial \mathrm{T}}{\partial \mathrm{z}}=\frac{1}{\mathrm{r}} \cdot \frac{\partial}{\partial_{\mathrm{r}}}\left(\mathrm{r} \cdot \lambda_{\mathrm{g}} \cdot \frac{\partial \mathrm{T}}{\partial_{\mathrm{r}}}\right)+\frac{\partial}{\partial \mathrm{z}} \cdot\left(\lambda_{\mathrm{g}} \cdot \frac{\partial \mathrm{T}}{\partial \mathrm{z}}\right)+\frac{\partial \mathrm{P}}{\partial \mathrm{t}}
$$

\subsection{Other Governing Equation}

\section{Reaction kinetics}

Based on previous studies (Kikkinides, Georgiadis \& Stubos, 2006; Kaplan \& Veziroglu, 2003), the following reaction kinetics is used for the modeling of the LaNi5-H2 system:

-for hydriding case

$$
(1-\varepsilon) \cdot \frac{\partial \rho_{s}}{\partial t}=C_{a} \cdot \exp \left(-\frac{E_{a}}{R_{g} \cdot T_{s}}\right) \cdot \ln \left(\frac{P}{P_{e q}}\right) \cdot\left(\rho_{\text {sat }}-\rho_{s}\right)
$$

- for dehydriding case 


$$
(1-\varepsilon) \cdot \frac{\partial \rho_{s}}{\partial t}=C_{d} \cdot \exp \left(-\frac{E_{d}}{R_{g} \cdot T_{s}}\right) \cdot\left(\frac{P-P_{e q}}{P_{e q}}\right) \cdot \rho_{s}
$$

Where $\rho$ sat is the density of the saturated metal hydride bed, i.e. after the reaction is completed.

The equilibrium pressure was calculated using the following equation:

\subsection{Modification of Model}

$$
\ln \left(\mathrm{P}_{\mathrm{eq}}\right)=\frac{\Delta \mathrm{H}}{\mathrm{Rg}_{\mathrm{g}}}-\frac{\Delta \mathrm{S}}{\mathrm{Rg}_{\mathrm{g}}}
$$

The modifications applied to the above model include :

1. Specific heat for Hydrogen gas was taken as function of temperature.

2. Viscosity variation as a function of hydride bed temperature.

3. Equivalent thermal conductivity as a function of diameter of hydride material.

4. Pressure of gas according to Darcy law is combined with momentum equations.

\subsection{Initial Conditions}

Initially the pressure, the temperature, and the metal hydride density in the tank are assumed to be constant, the tank is fully charged, and is in a state of equilibrium:

$$
\mathrm{T}(\mathrm{r}, \mathrm{z}, 0)=\mathrm{Ti}, \quad \operatorname{Pg}(\mathrm{r}, \mathrm{z}, 0)=\mathrm{Pi} \text { and } \mathrm{Ps}(\mathrm{r}, \mathrm{z}, 0)=\mathrm{Pi}
$$

\subsection{Boundary Conditions}

Top surface boundary conditions: $\quad \mathrm{Pg}=\mathrm{Pt} \quad$ and $\mathrm{T}=\mathrm{Tt}$ or $\mathrm{Kt} \frac{\partial \mathrm{T}}{\partial \mathrm{z}}=\mathrm{qt}$

Centre axis boundary conditions: $\quad \mathrm{Pg}=\mathrm{Pc}$ and $\mathrm{T}=\mathrm{Tc}$ or Kc $\frac{\partial \mathrm{T}}{\partial \mathrm{r}}=\mathrm{qc}$

Side surface boundary conditions: $\quad \mathrm{Pg}=\mathrm{Ps} \quad$ and $\mathrm{T}=\mathrm{Ts}$ or $\mathrm{Ks} \frac{\partial \mathrm{T}}{\partial \mathrm{r}}=\mathrm{qs} "$

Bottom surface boundary conditions: $\quad \mathrm{Pg}=\mathrm{Pb}$ and $\mathrm{T}=\mathrm{Tb}$ or $\mathrm{Kb} \frac{\partial \mathrm{T}}{\partial \mathrm{z}}=\mathrm{qb} "$

The following table (1) shows the properties of the materials were used in the simulation models in all of its stages.

\section{Results and Discussion}

Figures (2) show the model output for general LaNi5 material. The aim was to test the validity of the model. The model was found to predict the behavior of the tested hydride material as shown in [5].

This part discusses the initial screening test done to choose the best suitable material. In this part, several materials were selected and modeled for the hydrogen storage under the same conditions to try to find the best performing materials.

The main criterion for the selection used was the ability to store at moderate temperatures and pressures as well as less time. Other criteria which may be used for the selection can be the volume of canister needed to store certain amount of hydrogen.

In this project the first two were selected. The materials used in this study were selected after thorough search in the available literature as well as the available materials locally in Jordan. Modeling was done with the help of specialized software designed for fuel cell testing e.g. PDESol.

Table 1. Properties of Materials Use in Modeling

\begin{tabular}{lccccc}
\hline Materials & $\begin{array}{c}\text { Thermal conductivity } \\
(\mathrm{W} / \mathrm{mK})\end{array}$ & $\begin{array}{c}\text { Specific heat } \\
(\mathrm{J} / \mathrm{kg} . \mathrm{K})\end{array}$ & $\begin{array}{c}\text { Density } \\
\left(\mathrm{kg} / \mathrm{m}^{3}\right)\end{array}$ & $\begin{array}{c}\text { Young's modulus } \\
(\mathrm{GPa})\end{array}$ & $\begin{array}{c}\text { Poisson } \\
\text { ratio }\end{array}$ \\
\hline Lanthanum & 13.4 & 190 & 6162 & 36.6 & 0.28 \\
Magnesium & 156 & 102 & 1738 & 45 & 0.29 \\
Nickel & 90.9 & 440 & 8908 & 200 & 0.31 \\
Sand & 0.2452 & 710 & 830 & - & - \\
\hline
\end{tabular}


The results of the initial screening is presented below in Figures (3). The hotness of the materials refer to the absorption reaction between the material and hydrogen. As can be noticed, Sweileh sand and Magnesium showed the best performance (though at the cost of high temperature) and the best storage capacity compared with other materials like Nickel and Lanthanum.

Though Lanthanum showed relatively cooler behavior, however the storage capacity was not as showed by other materials.

Therefore, the three best performing materials selected for the next screening test were Magnesium, Lanthanum and Sweileh sand. The next step taken in this project was the attempt to find the best combination between the two selected materials.

As an initial test, mixtures of $50-50 \%$ was selected and their respective properties were calculated by linearly interpolating the properties of each one.

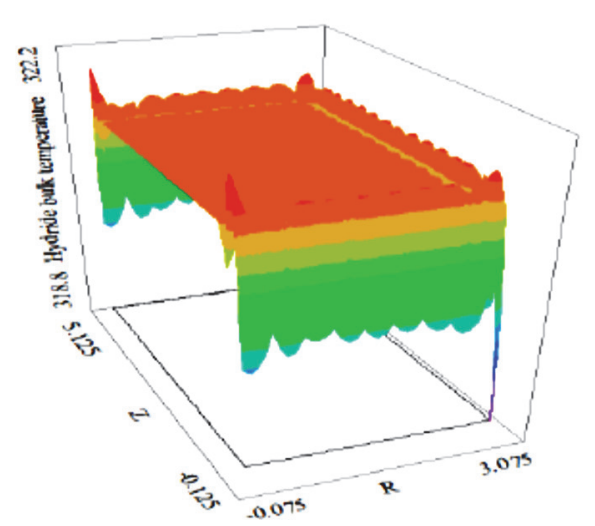

Ryandac buik temperature
$(-5.53 .-14.5 .30 .5$

(a) Temperature distribution in the canister.

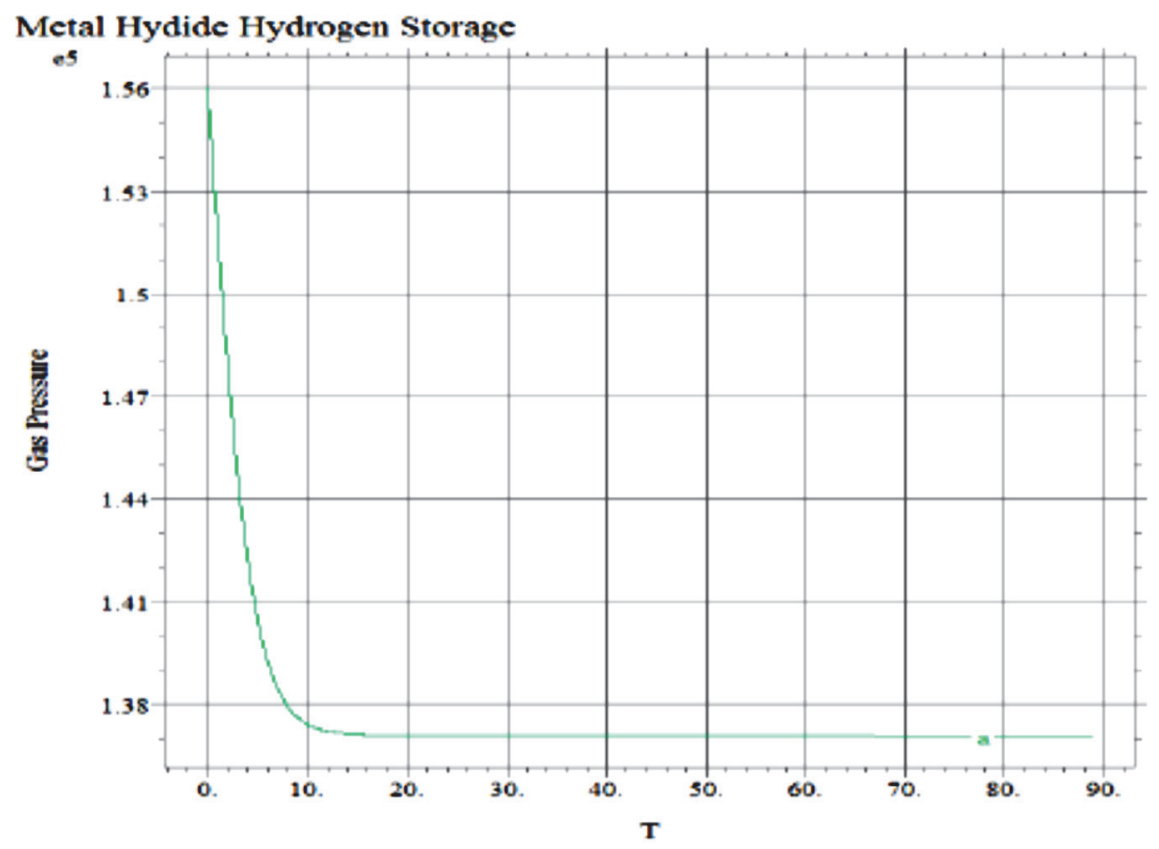

(b) Hydrogen gas pressure variation with time 


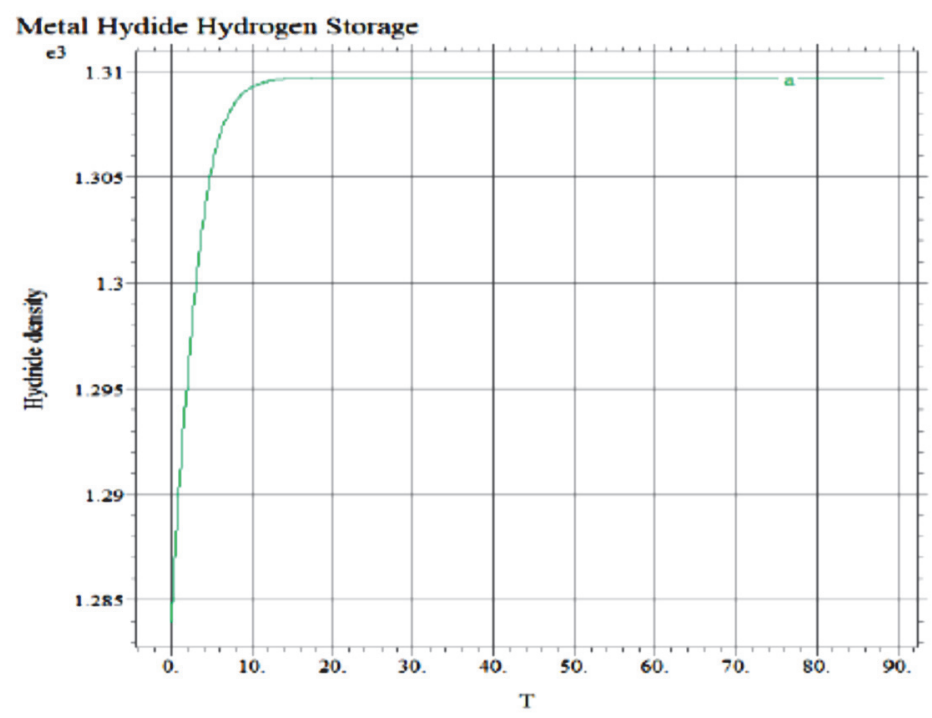

(c) Metal hydride density variation with time

Figure 4. Model output data

These data were fed to the model and the results were as shown in Figures (4). It was clearly shown that the addition of sand to Lanthanum and Magnesium was an added advantage because as shown, it showed best storage capacity at lower temperatures. The combination of Lanthanum and Magnesium did not show competitive results as shown by others.

The last step in this initial screening was to find out which is more effective in hydrogen storage, is it the Sand or other materials. For this purpose, $25-75 \%$ of the materials mixtures were selected and again their respective properties were calculated by linear interpolation.

As clearly shown in Figures 4 the addition of Magnesium was more effective to the adsorption reaction than that of Sweileh sand. This is in total agreement with the available literature.

According to Temperature distribution, the amount of absorption of hydrogen is better when we use the higher percentage of Magnesium.

The original model was modified with the use of variable specific heat and viscosity equation for hydrogen to accommodate for the temperature and pressure change during the process. Figures $(5, a, b, c, d$ and e) show the temperature variation throughout the absorption process.
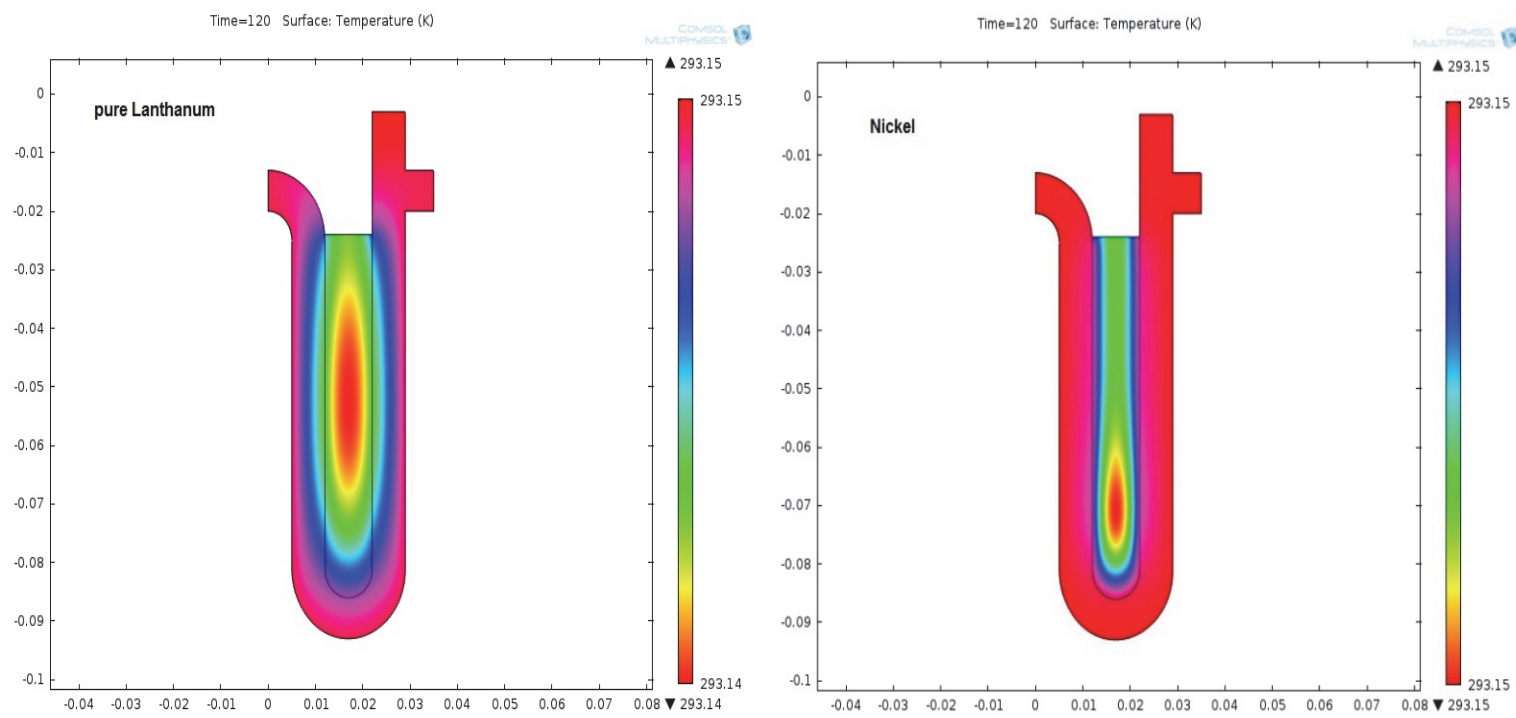

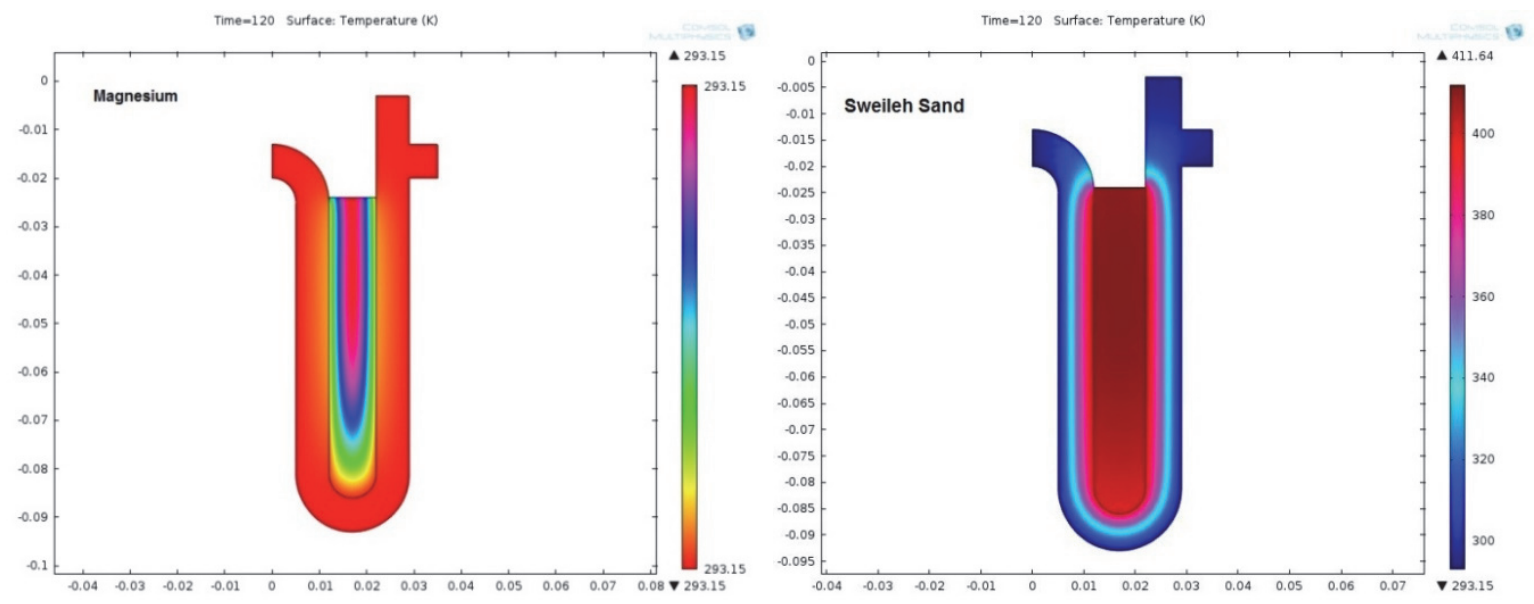

Figure 5. The amount of absorption for different pure materials

It is clearly noticed that Magnesium was the most uniform with maximum temperature rise during the adsorption process. This is clear indication that the amount of reaction that took place with $\mathrm{Mg}$ was higher than others. This means that the amount of hydrogen stored was higher than other materials. This is a clear advantage of the material as it will help in easily release the stored hydrogen during the desorption process. This is clearly shown in Figure (5-a).

Sand, on the other hand, shown in Figure (5-b), showed relatively lower temperature rise compared with Mg. This means that the amount of hydrogen stored was low compared with Mg. And hence, less hydrogen will be evolved during the desorption process. This is expected since the properties of sand are not as superior as that for $\mathrm{Mg}$. This is shown in Table (1).
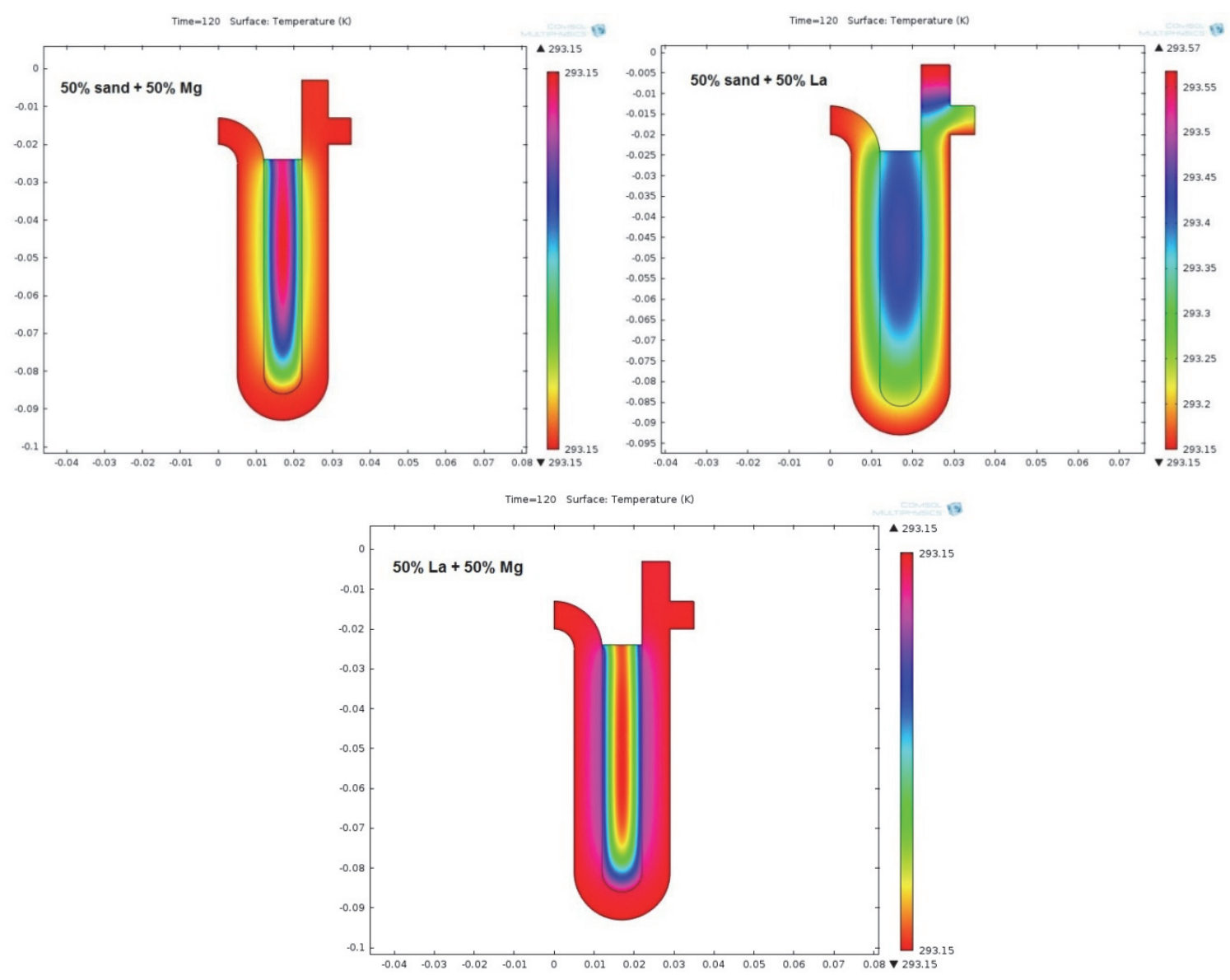

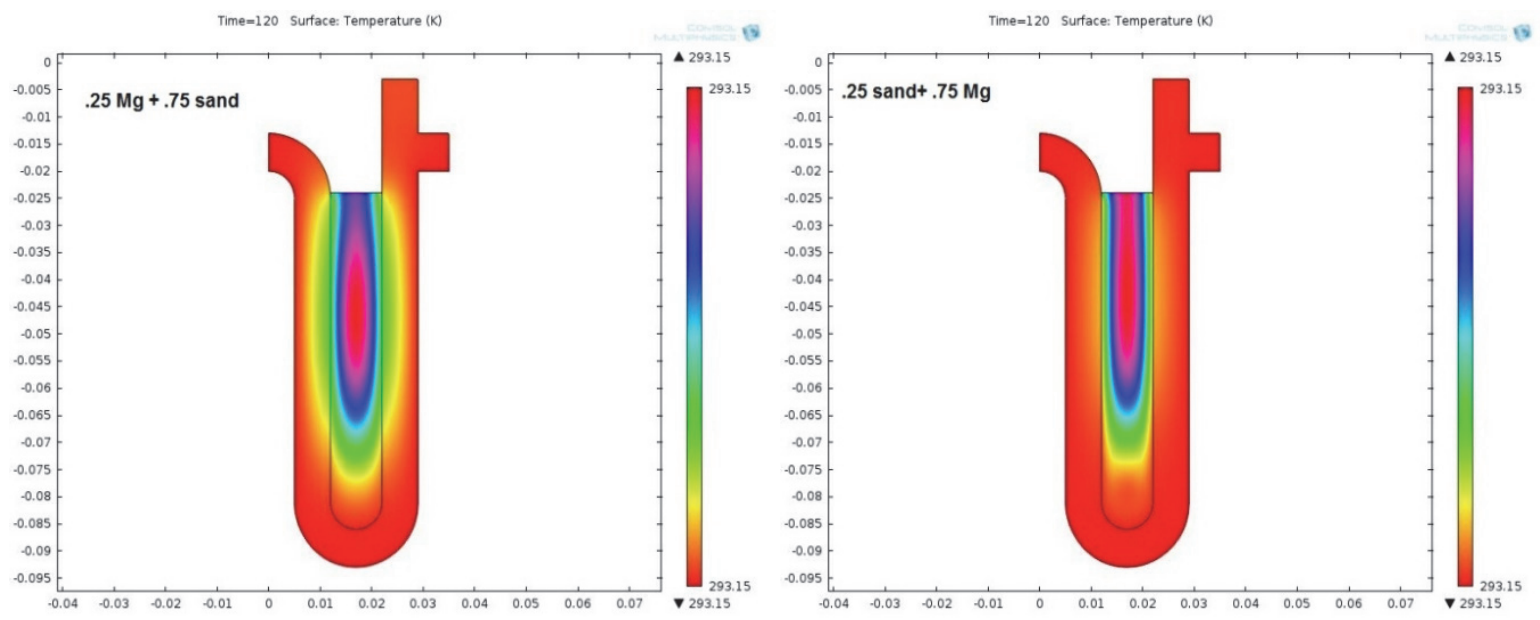

Figure 6. The amount of absorption for different percentage of sand and Mg mixture

a) Magnesium (pure)

Metal Hydide Hydrogen Storage
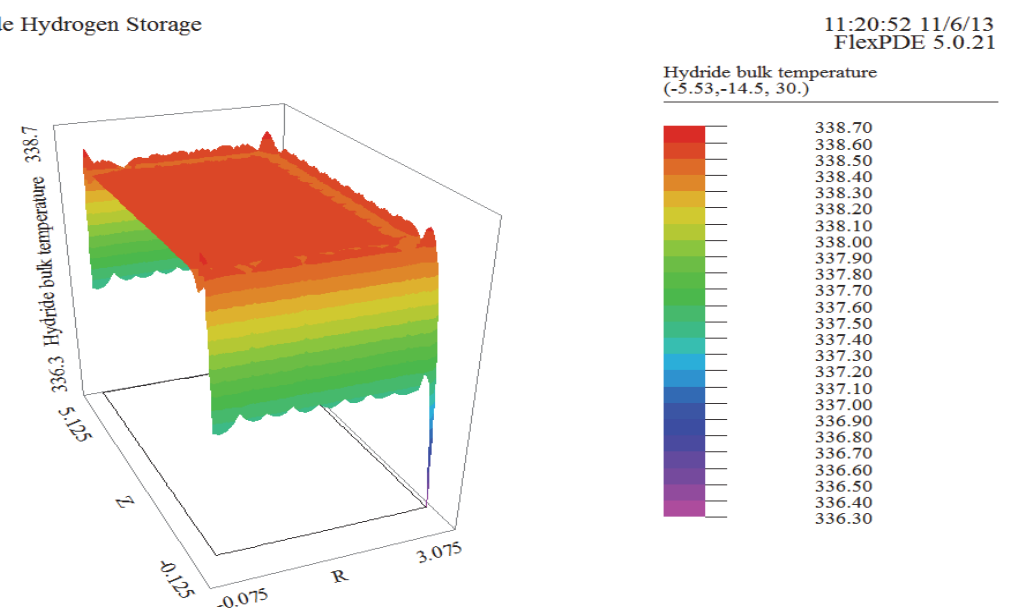

Metal Hydride New OK: Cycle $=2179$ Time $=108.55 \mathrm{dt}=0.0478$ p2 Nodes $=693$ Cells $=322$ RMS Err $=6.4 \mathrm{e}-6$ Vol_Integral= 47843.92

b) Sand (pure)

Metal Hydide Hydrogen Storage

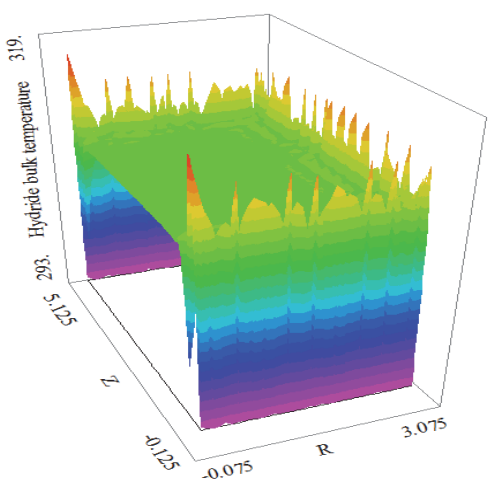

Metal Hydride New OK: Cycle $=2413$ Time $=120.00 \mathrm{dt}=0.0490$ p2 Nodes $=807$ Cells $=368$ RMS Err $=1.7 \mathrm{e}-7$ Vol Integral $=43720.91$
12:46:08: 10/26/13
FlexPDE 5.0 .21

$\underset{(-5.53,-14.5,30 .)}{\text { Hydride bulk temperature }}$

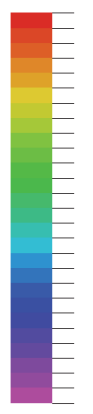

319.0
318.0
317.0
316.0
315.0
314.0
313.0
312.0
311.0
310.0
309.0
308.0
307.0
306.0
305.0
304.0
303.0
302.0
301.0
300.0
299.0
298.0
297.0
296.0
295.0
294.0
293.0 
c) $50 \%$ sand, $50 \% \mathrm{Mg}$

Metal Hydide Hydrogen Storage

12:07:36 10/27/13
FlexPDE 5.0.21

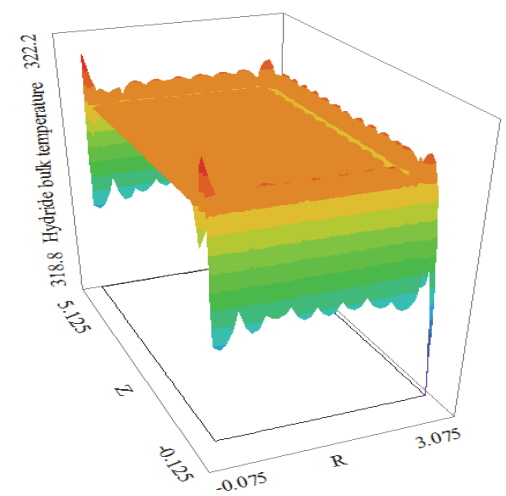

Hydride bulk tempcrature

Metal Hydride New OK: Cycle $=1772$ Time $=88.200 \mathrm{dt}=0.0478$ p2 Nodes $=693 \mathrm{Cells}=322 \mathrm{RMS}$ Err $=8.5 \mathrm{e}-6$
Vol Integral $=45460.23$

d) $75 \%$ sand, $25 \% \mathrm{Mg}$

Metal Hydide Hydrogen Storage

12:15:04 10/26/13
FlexPDE 5.0.21

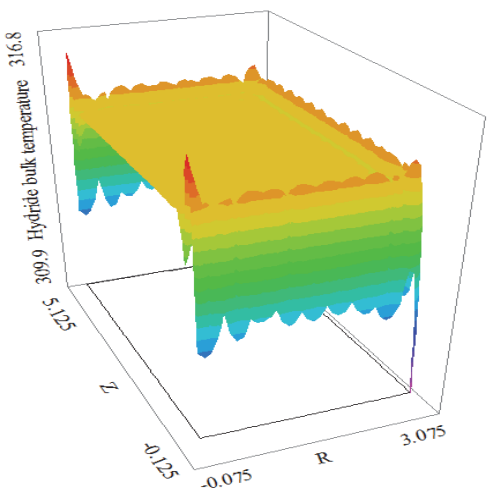

Metal Hydride New OK: Cycle $=2408$ Time $=120.00 \mathrm{dt}=0.0478$ p2 Nodes $=693$ Cells $=322$ RMS En $=6.1 \mathrm{e}-6$
Vol_Integral=44564.52

e) $25 \%$ sand, $75 \% \mathrm{Mg}$

Metal Hydide Hydrogen Storage

17:57:43 10/26/13
FlexPDE 5.0.21

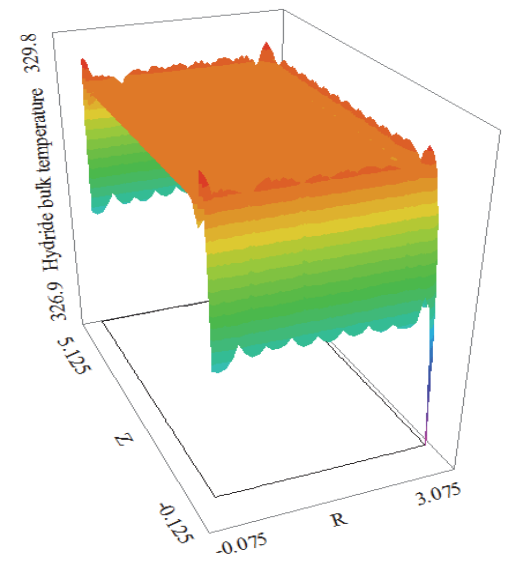

$\underset{(-5.53,-14.5,30 .)}{\text { Hydride bulk temperature }}$

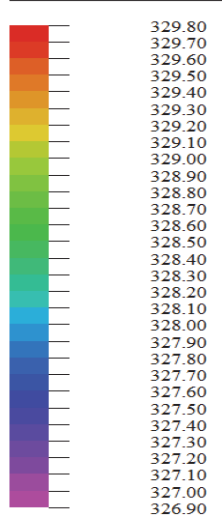
Metal Hydride New OK: Cycle $=2408$ Time $=120.00 \mathrm{dt}=0.0478 \mathrm{p} 2$ Nodes $=693 \mathrm{Cells}=322 \mathrm{RMS}$ Err $=6 . \mathrm{e}-6$
Vol_Integral= 46562.71

Figure 7. Temperature Variation throughout the Absorption Process 
Figures 7 further show that the absorption properties improved with the addition of $\mathrm{Mg}$ in the mixture. This is expected since the addition of $\mathrm{Mg}$ improves the absorption kinetic reaction. Based on the samples studied, $75 \% \mathrm{MG}+25 \%$ Sand was the best.

\section{Conclusion}

After studying the different materials available in Jordan it is concluded that no single material shall be used for hydrogen storage; rather a mixture of several materials may be better for good hydride performance. It is also concluded that $\mathrm{Mg}$ is recommended to be used with other materials for better hydrogen storage capacity.

\section{Acknowledgement}

The authors would like to thank Dr Sofoklis Makridis for his kind help by allowing us to use COMSOL and the Metal hydride model he developed. Authors also like to extend their thanks to Mazyouna Rashad Al-Sayed, Borouj Bssam Al-Tarawneh, Dema Hussien Al-Nsour and Wala'a Mohammad Ali-Hasan for the help they offered during this study.

\section{References}

Assanbayeva, M. (2009). Modelling, Design and Control Optimization of Hydrogen Storage Systems (Doctoral dissertation, Imperial College London London).

Jemni, A., Nasrallah, S. B., \& Lamloumi, J. (1999). Experimental and theoretical study of ametal-hydrogen reactor. International Journal of Hydrogen Energy, 24(7), 631-644. https://doi.org/10.1016/S0360-3199(98)00117-7

Kaplan, Y., \& Veziroglu, T. N. (2003). Mathematical modelling of hydrogen storage in a LaNi5 hydride bed. International Journal of Energy Research, 27(11), 1027-1038. https://doi.org/10.1002/er.919

Khammash, T. (2012). The Jordanian Energy Sector. Sector report by Jordinvest, 2012.

Kikkinides, E. S., Georgiadis, M. C., \& Stubos, A. K. (2006). On the optimization of hydrogen storage in metal hydride beds. International Journal of Hydrogen Energy, 31(6), 737-751. https://doi.org/10.1016/j.ijhydene.2005.06.021

Madanat, M., Kailani, G., \& Mehyar, N. (1998). Evaluation of Ras En Naqb glass sand. Retrieved from http://emrc.gov.jo/images/zeolitic_tuff.pdf

\section{Copyrights}

Copyright for this article is retained by the author(s), with first publication rights granted to the journal.

This is an open-access article distributed under the terms and conditions of the Creative Commons Attribution license (http://creativecommons.org/licenses/by/4.0/). 